\title{
Flood-risk assessment and hazard mitigation measures: case studies and lessons learnt in Italy
}

\author{
S. Mambretti ${ }^{1}$, D. De Wrachien ${ }^{2} \&$ A. Sole ${ }^{3}$ \\ ${ }^{I}$ DIIAR, Politecnico di Milano, Italy \\ ${ }^{2}$ Department of Agricultural Hydraulics, State University of Milan, Italy \\ ${ }^{3}$ DIFA, Università degli Studi della Basilicata, Italy
}

\begin{abstract}
The effect of climate change and the growing world population are together increasing both the chance of flooding and the consequences. There is mounting recognition that reliance on structural flood defences alone may be neither sufficient nor sustainable in the long term, particularly in low lands.

In Italy, in the wake of the floods that plagued the northern part of the country in the fifties and sixties, a process was set in motion aimed at developing a new integrated approach to water management, at the catchment level, suitable for coping with water related disasters.

In this context, three case-studies of flood risk management and hazard assessment are featured: two related to the Po catchment and the last to the Basento river in the Basilicata Region. After describing the methodologies, which differ in the application effort required and in the accuracy expected, the paper focuses on both the results achieved and the reliability of the procedures applied. Management issues are approached under four general headings: planning, technical, operational and institutional.

Although the cases differ with respect to the flooding problems they encounter, some common issues emerged: the challenge of translating a riskbased approach on a basin-wide level into concrete measures, harmonizing flood-risk management policy with spatial planning and institutional cooperation.
\end{abstract}

Keywords: flood management in Italy, new policy approach, country casestudies. 


\section{Introduction}

Floods are among the most damaging of natural hazards, and are likely to become more frequent, more relevant and most serious in the future due to the effects of climate change and urbanization. To cope with these hazards, it is imperative that human society adopts an effective flood hazard management approach whose aim is to develop a set of structural and non-structural measures suitable for reducing the damage to an acceptable level and to maximize the efficient uses of flood-prone land. To do this, it is necessary to integrate river basin management and flood hazard mitigation strategies into the broader context of catchment management both in terms of land and water management. To this end, the best solution is to regard the different measures as complements, rather than as alternatives.

The use of a portfolio of mixed measures is always preferable because of the risk of failure of any single strategy. A fundamental stage of the process of evaluating and choosing a possible portfolio of measure should be an assessment of what will happen when it fails. It is therefore necessary to consider the effect of the whole intervention strategy across the entire spectrum of flood events at the river basin level. As a matter of fact interventions are usually targeted at reducing the impact of frequent floods in a particular area, but the impacts of these interventions on more extreme events must also be considered.

The resulting portfolio of mixed measures is, generally, known, as the "Integrated Water Management" approach [6].

This framework allows good opportunities to combine water management with objectives of other policy sectors, including the reconstruction of rural areas, maintenance of ecological infrastructures, land use, residential construction and development of parks; moreover, it offers a crucial qualitative impulse to the spatial planning for the countries where it is adopted [3].

To properly cope with these challenges new knowledge is required on flood forecasting, risk computation and methods of spatial planning compatible with flood management. More effort must be put into damage mitigation and flood defence operations. Moreover, the intergenerational timescales for sustainability assessments pose additional questions of how to account for future changes of both the environment and the society and how to handle the uncertainty in the decision-making processes.

In Italy, in the wake of the floods that plagued the northern part of the Country in the fifties (Polesine, Po valley) and in the sixties (Florence, Arno river catchment), to provide a remedy for the deficiencies in policy and strategy dealing with water-related disasters, a process was set in motion aiming at developing a new integrated approach to water management - at the catchment level - suitable to serve as a framework designed to prevent, mitigate, prepare for, respond to and recover from the effects of floods and other water-related disasters. This framework, known as "River Authority", was designed to cope with water management and flood hazard mitigation issues within each of the main Italian catchments. 
Three case studies of flood risk-management and hazard assessment are described hereunder. They concern, respectively, the Lambro river in the vicinity of the city of Milan, the San Benedetto Po municipality, near Mantova, where a stretch of the Po river was studied, and the Basento river, in the Basilicata region.

\section{Methods and models}

Various methods can be used to identify potentially flooded areas and assess the respective hazards. The simplest ones are based on morphologic parameters, such as land levels and slopes, distance from the river and so on, whilst the more complex tools are represented by mathematical models suitable to describe the behaviour of these physical phenomena $[1,2]$.

Briefly, this evaluation may: (a) be limited to an overview of the historically flooded areas, based on existing data; (b) localize the topographical areas below the level of the water depth in the river, estimating the latter through the peak discharge for a given return period; (c) use a combination of parameters, such as level and distance from the flood origin, with approximate methods; (d) resort to a two-dimensional complete model based on the shallow water flow equations. The maps of previous floods can be very useful in both determining flood-prone areas and calibrating more complex models.

A good understanding of a complex flooding event can only be achieved by means of 2D hydrodynamic models based on the shallow-water or the De Saint Venant (SV) equations. These codes provide the spatial-temporal characteristics (i.e. water depth and velocity) of the wave which flows out of the breakage and floods the surrounding low land.

Mass and momentum for 2D-SV equations can be expressed as:

$$
\begin{gathered}
\frac{\partial h}{\partial t}+\frac{\partial h V_{x}}{\partial x}+\frac{\partial h V_{y}}{\partial y}=i \\
\left\{\begin{array}{c}
S_{f x}=S_{0 x}-\frac{\partial h}{\partial x}-\frac{V_{x}}{g} \cdot \frac{\partial V_{x}}{\partial x}-\frac{V_{y}}{g} \cdot \frac{\partial V_{x}}{\partial y}-\frac{1}{g} \cdot \frac{\partial V_{x}}{\partial t} \\
S_{f y}=S_{0 y}-\frac{\partial h}{\partial y}-\frac{V_{y}}{g} \cdot \frac{\partial V_{y}}{\partial y}-\frac{V_{x}}{g} \cdot \frac{\partial V_{y}}{\partial x}-\frac{1}{g} \cdot \frac{\partial V_{y}}{\partial t}
\end{array}\right.
\end{gathered}
$$

with $h$ : water depth; $i$ : rainfall intensity; $V_{x}, V_{y}$ : water velocities in the $x$ and $y$ directions; $S_{f x}, S_{f y}$ : roughness terms; $S_{0 x}, S_{0 y}$ : landslope.

The preliminary phase of the simulation process deals with the construction of a grid which is superimposed to a detailed map of the potentially flooded area. Each mesh of the grid has to be characterised by both the elevation of the land and the roughness coefficient.

Anyhow, all methods need an accurate and critical analysis and their application to real cases should be performed by well trained personnel. Moreover, a continuous interaction between the territorial planner and the hydraulic engineer is required. 
With regard to the plans, it is important to remind that the "River Authorities", for the most important catchments, defines the "A", "B" and "C" bands which are drawn around the river to border the different hazard levels. In particular, the " $\mathrm{A}$ " band is positioned to the limits of the flooding due to a discharge equal to the $80 \%$ of the one of 200 years return period; the " $\mathrm{B}$ " band is the same, but with a discharge $100 \%$ of 200 years return period; the " $\mathrm{C}$ " band is positioned to the limits of the flooding due to a discharge with return period equal to 500 years, or, if available, an historical value which gave a disaster in the area.

While within the limits of the bands " $A$ " and " $B$ " the urbanisation is ruled by the "River Authority" (and strictly prohibited or limited to necessary maintenance of existing building), the activities within the " $\mathrm{C}$ " band have to be ruled by the Municipalities. The "C" band is divided in different regions with a different degree of hazard (and so with different rules related to the possibility of urbanisation), because they are usually very large and the impediment of using that large areas would bring an economic loss.

\section{Case studies}

\subsection{The Lambro river case study}

In Milan the flood prone area of the Lambro river has been studied. A twodimensional model, based on the De Saint Venant equations, has been built and calibrated using recording of a large flood happened in 1951.

An area, of about $20 \mathrm{~km}^{2}$, has been divided in squared cells of $50 \mathrm{~m} \times 50 \mathrm{~m}$, each characterised by the ground elevation and the Manning roughness coefficient. Simulations have been carried out with three different discharge values: one for the incipient flood, one for a flood of 200 years return period, and the last with a 500 years return period discharge.

The model gives the depth and velocity for each cell, function of the time. Maximum values of depth and velocity have been computed for each cell and to each cell a degree of hazard has been assigned, ranging from 1 (less dangerous) to 4 (extremely dangerous).

On this basis, the Milan Municipality issued the following technical rules:

- in the areas with hazard in class 1, no particular reasons against further urbanisations have been determined;

- in the area with hazard 2 (medium risk), new urbanisation is still possible, but the Municipality may require specific studies about hydro-geological features, and it may also be required to build defensive structures;

- in the area with hazard 3 (high risk) applications for new buildings must be equipped with documents concerning the hydro-geological conditions; together with plans for hydraulic and structural safety;

- in the area with hazard 4 (very high risk) no new urbanisations are allowed, and works are permitted only in order to reduce the vulnerability of existing buildings. Strictly forbidden are all the chemical and petrol-chemical activities along with garbage dumps. 


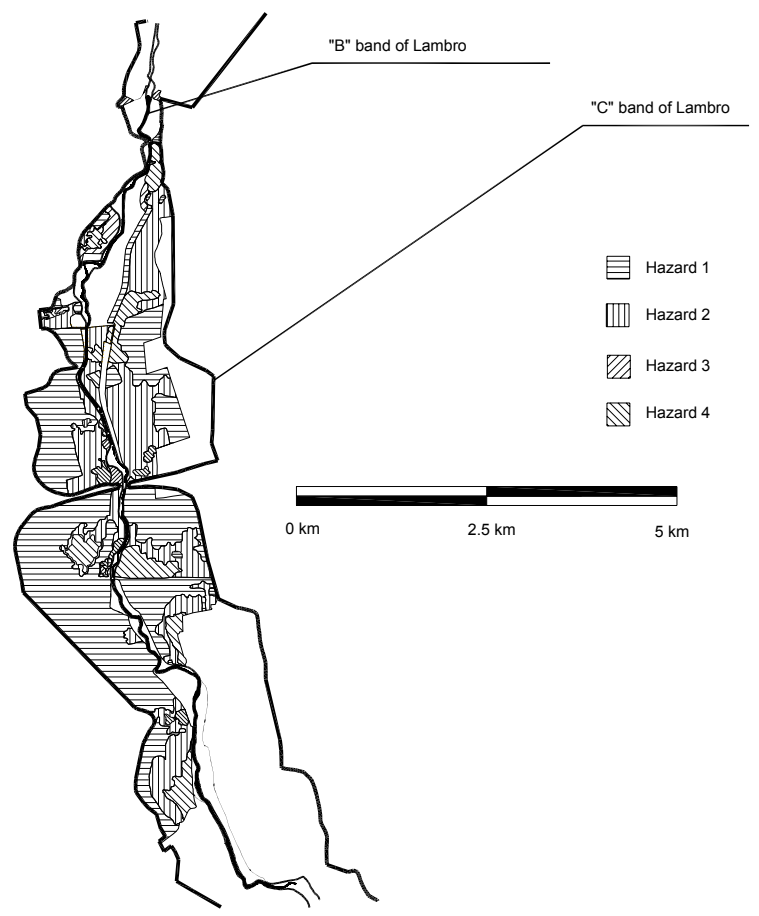

Figure 1: $\quad$ Hazard classes near the Lambro River in Milano.

Figure 1 shows the different hazard classes within the area where flood are expected.

\subsection{The San Benedetto Po case study}

A 2D model based on De Saint Venant equations was applied for the San Benedetto Po municipality, near Mantova, where a stretch of the Po river has been studied.

In this area the Po river flows in a completely flat landscape (slopes being of about 1\%o); the river is pensile and main embankments are present. In the stretch, the low zone is about $500 \mathrm{~m}$ wide and the distance between the main embankments is about $1 \mathrm{~km}$.

Despite considerable re-embankment work along the main river and its tributaries, the environmental feature of San Benedetto Po is still critical from an hydraulic point of view. For these reasons the use of the described methods requires some different hypothesis. First, the topographic method cannot be used owing to the landscape; in fact, for pensile rivers this method leads to unacceptable overestimations of flooded areas. On the other hand, when embankments are present, it is necessary to analyse different scenarios, assuming the breakage of the bank in different positions and in different situations. 
In the present case, the area to be investigated is about $90 \mathrm{~km}^{2}$. The choice of the area was based on historical events and on the characteristics of the landscape, that has low ground levels and is narrowing between Po and the embankments of the Secchia river.

A regular $100 \mathrm{~m}$ square grid has been superimposed to a topographic map of the potentially flooded area. The chosen grid is a compromise between the desired detail level and the computational effort (due to the extension of the area); moreover this choice is justified because of the landscape, which is very flat, with ground levels varying between 15 and $18 \mathrm{~m}$ a.s.l., so that a major detail would not bring more significant results.

The embankment breakage was simulated as a breach of $100 \mathrm{~m}$ width and 4.5 $m$ height, occurring when the water level in the river reaches $21 \mathrm{~m}$ a.s.l. The output from the river bed was simulated as the flow through a broad crested weir.

In order to evaluate the output hydrograph from the breach, the wave in an upstream cross section of the river was computed. This hydrograph formed the basis for computation of water depths in the section concerned using Chézy's formula (steady flow hypothesis). It was found that lamination phenomena between the two sections ( distance about $20 \mathrm{~km}$ ) were negligible, due to the fact that the volume that could be stored in the flood plain areas was very small compared to the total wave volume.

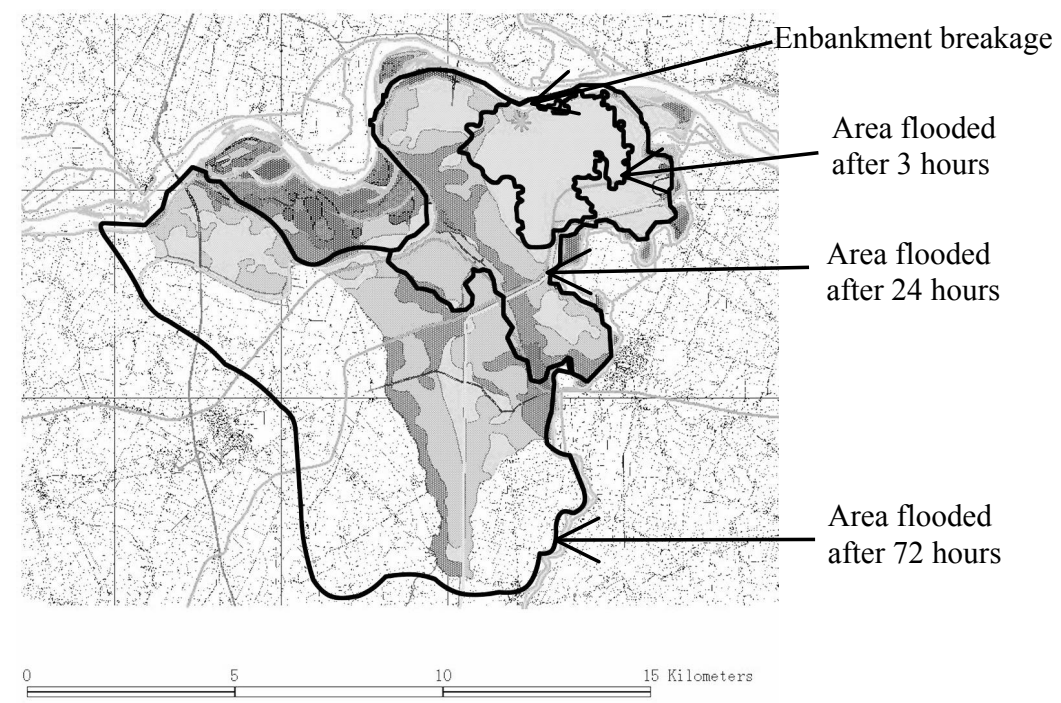

Figure 2: $\quad$ Simulated area and position of the embankment breakage.

The total volume of the wave with 200 years return period was assessed at about $4.6 \cdot 10^{9} \mathrm{~m}^{3}$. The maximum discharge flowing from the breach was $979 \mathrm{~m}^{3} / \mathrm{s}$ while the ground level of the matching cell (equal to the bottom of the breach) was 19 m a.s.l. 
The area is reported in figure 2 .

The figure shows that the potentially flooded area lies between the embankments of the Po river (to the North-East) and those of the Secchia river (to the East). The North-East zone in this area is the lowest and, as a consequence, owns the deepest water depths. A further restriction to the wave flow is the railway, which crosses the municipality landscape from North-West to South-East, following the southern boundary of the area where the greatest water depths are found. Other facilities ,such as highways and pensile canals, seem not to influence in significant way the wave propagation due to their limited heights.

The results show that the wave reaches the town 24 hours after the embankment breakage; this result plays a role of paramount importance in emergency planning.

Flooded volumes and areas are respectively equal to $8.06 \cdot 10^{8} \mathrm{~m}^{3}$ and $6.6 \cdot 10^{7} \mathrm{~m}^{2}$.

It can be observed that the wave, after overcoming structures of minor importance, is also able to flood the railway, which is placed $6 \mathrm{~km}$ from the breakage and at a ground level of $19 \mathrm{~m}$ a.s.l.

\subsection{The Basento case study}

This study is included in a larger investigation that comprises all rivers of the Basilicata Region [7]. The Basento river is $157 \mathrm{~km}$ long, with a catchment of $1535 \mathrm{~km}^{2}$ (figure 3). The aim was to assess the flooding risk for the whole region, in order to comply with the Italian land protection legislation, defined by the regional Authority by means of the Hydro Geologic Safety Plan (PAI). This plan aims to identify the different risk zones and to devise and work out flooding area maps for flow rates corresponding to different return periods.

Four codes have been used for the simulation: Hec Ras, Mike 11 and Mike 21 (Danish Hydraulic Institute) and FLO-2D [5] in order to compare the effectiveness of the different tools and to identify the most appropriate one.

The 1D simulations have been carried out using field data of more than 650 river cross sections (including bridges, culverts, weirs and other hydraulic works) in order to assess both the geometric characteristics of streams and peak flows with 30, 200 and 500 years return period, respectively, and to use as upstream boundary conditions for the 2D simulations.

It is worth underline that integration between hydrodynamic model and detailed field data (as laser scanning data) is quite difficult and requires a great deal of preprocessing work. To this end, values of both water-surface elevation and top width in river bed, obtained within the simulation process, have been used in the GIS procedures, to draw up maps of different flooded areas. These results are shown in figure 4 that depicts the main stream, along with the cross sections analysed and the flood risk areas for the above mentioned return periods.

The differences between the simulations of the two 1D models reflect the differences between the solvers of the model's basic equations. Anyhow, these differences are meaningless, taking into account the scale of the maps (1:5000 scale, $5 m$ contour line). 


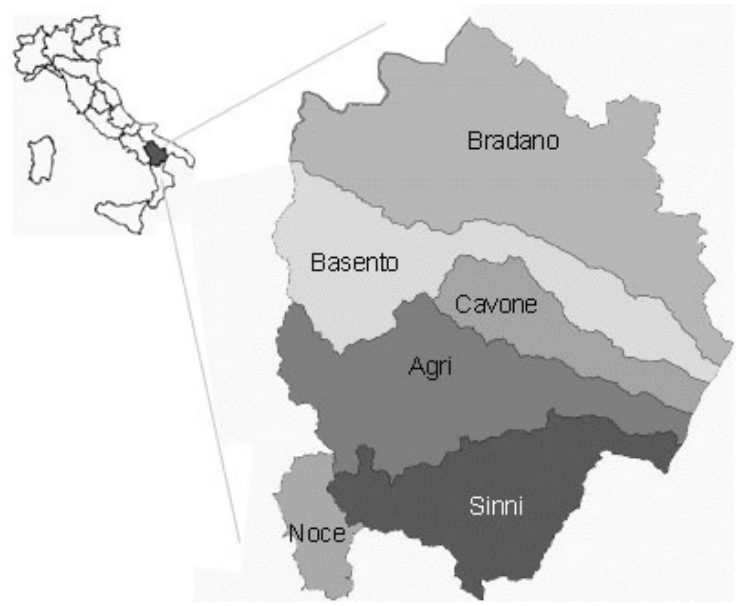

Figure 3: $\quad$ Study area, Basilicata region.

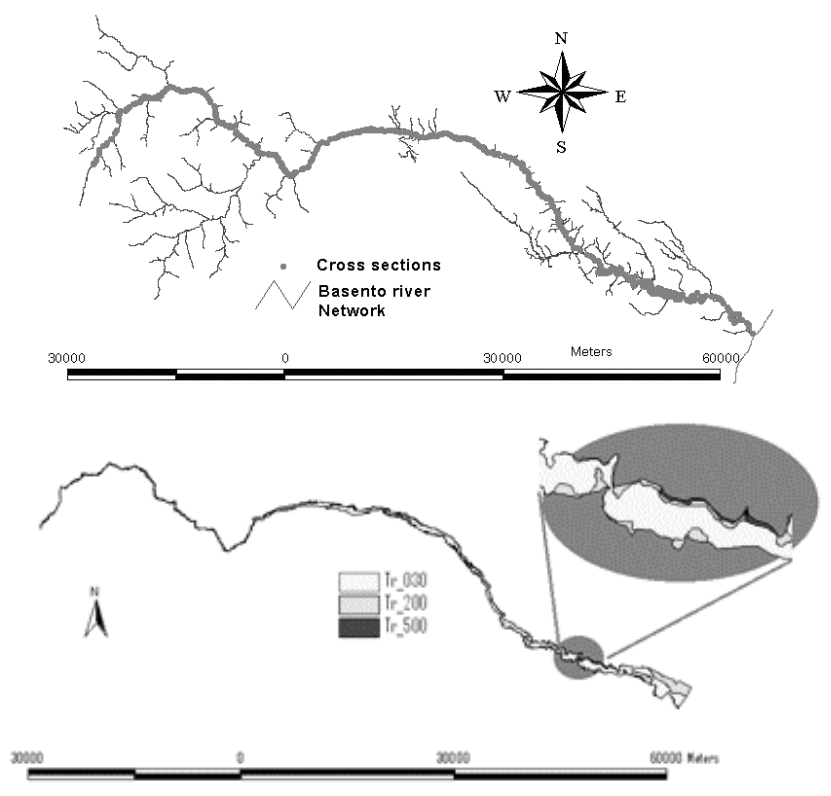

Figure 4: Basento river: (above) river network and cross section position and (below) flooded areas.

The area investigated covers a strip of about $3.5 \mathrm{~km}$ on both the left and right sides of the river. The set of topographic data, obtained by means of laser scanning [4] was used to generate the Digital Surface Model (DSM), which allowed to design a Key Points Model (KPM) - containing data of paramount importance for topographic maps - and depict the bathymetry of the investigated area (figure 5). 

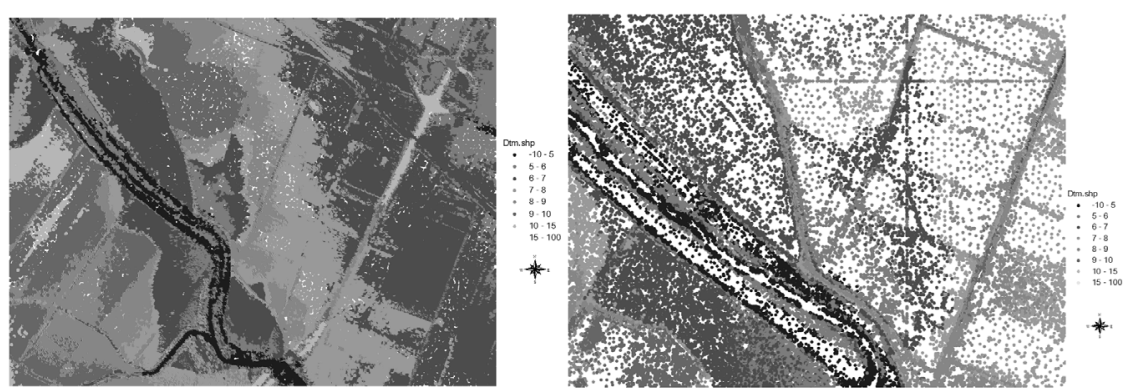

Figure 5: (left) Digital surface model and (right) model keypoints.

With regard to the 2D models, figure 6 shows the differences between two flooded areas (return period equal to 30 years) obtained by means of Mike 21 and FLO-2D models.

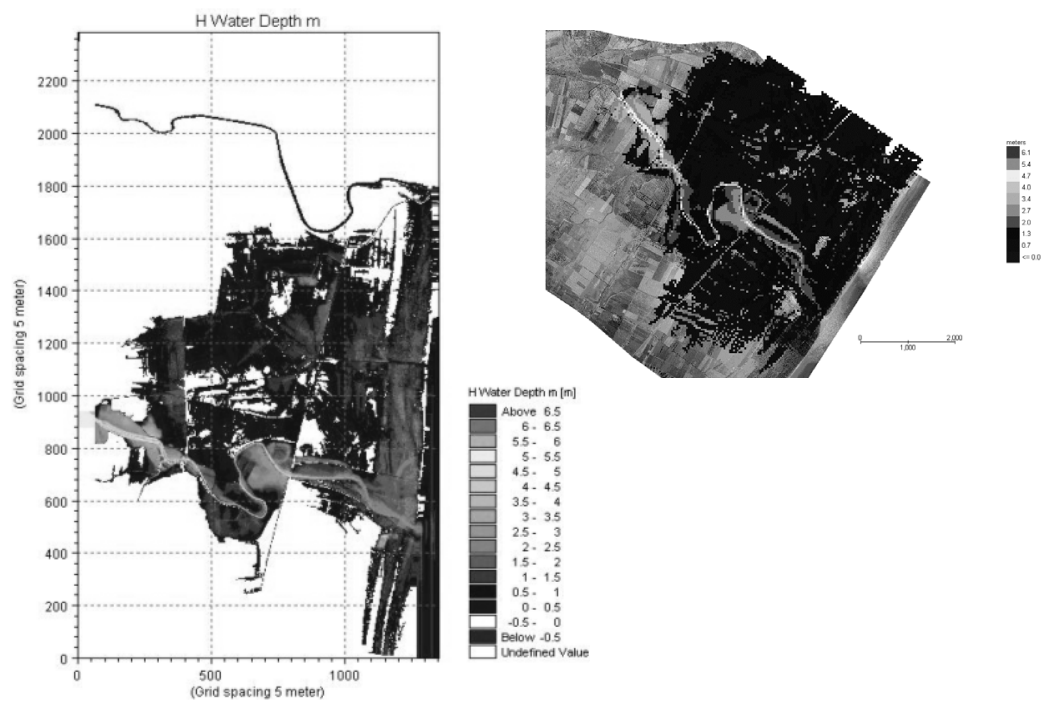

Figure 6: Basento river: inundation maps for flood with 30 years return period; (left) Mike 21 and (right) FLO-2D results.

\section{Conclusions}

In Italy, in the wake of the floods that plagued the Country in the fifties and sixties, a process was set in motion, aiming at developing a new integrated approach to water management - at the catchment level - suitable to serve as a framework - known as "River Authority" - designed to cope with flood hazard mitigation issues within each of the main Italian River Basins. In this context, three case studies of flood-risk management and hazard assessment have been featured. They concern, respectively, the Lambro river, in the vicinity of the city 
of Milan, the San Benedetto municipality, near Mantova, and the Basento river, in the Basilicata region. These studies underline that knowledge and advanced scientific tools play a role of paramount importance in the strain of coping with flooding problems, along with the capacity building within a political and administrative background. Therefore, the central government and the River Authorities need to establish clear institutional, financial and social mechanisms in order to ensure the safety of people and property and, thereby, to contribute to flood defence and sustainable development. In this way a harmonious coexistence with floods can be achieved.

\section{References}

[1] D. Bagioli, E. Larcan, S. Mambretti Flooding Hazards in Northern Italy Two Cases Studies. Second International Conference on Sustainable Planning and Development, Bologna, Italy, 12 - 14 September 2005

[2] D. Berzi, A. Colucci, S. Mambretti: Sustainable development and risk. 2. Flood hazard and vulnerability assessment. Methodological proposal and application. First International Conference on Sustainable Planning and Development, 1 - 3 September 2003, Skiathos, Greece

[3] De Wrachien D., Mambretti S., Sole A., Risk Analysis and Vulnerability Assessment in Flood Protection and River Basin Management, FRIAR 2008, 2 - 3 July 2008, London, United Kingdom

[4] Giosa L. Tecnologia laser scanner e modelli idraulici per la valutazione del rischio di inondazione nelle pianure costiere (in Italian) $\mathrm{PhD}$ thesis, Potenza, Italy, 2007

[5] O'Brien J. FLO - 2D User Manual Version 2007

[6] Rijkswaterstaat $A$ different approach to water policy in the 21st Century, The Hague, 2000

[7] Sole A., Giosa L., Copertino V.: Risk flood areas, a study case: Basilicata Region, in River Basin management IV, C. A. Brebbia, K. Katsifarakis eds, ISBN: 978-1-84564-075-0; WIT Transactions on Ecology and the Environment, V. 55, suppl. 1, pp 3-8, 20 